\title{
Whey protein supplementation for the preservation of mass and muscular strength of patients with heart failure: study protocol for a randomized controlled trial
}

Elisa Maia dos Santos ${ }^{1,7^{*}}$, Roger de Moraes², Eduardo Vera Tibiriça ${ }^{3}$, Grazielle Vilas Bôas Huguenin ${ }^{4,5}$, Annie Seixas Belo Moreira ${ }^{6,7}$ and Andrea Rocha De Lorenzo ${ }^{1,7}$

\begin{abstract}
Background: Heart failure (HF) is an important public health problem, considered a new epidemic with high morbidity and mortality. The progression of HF often determines weight reduction, muscle mass loss, and reduced physical ability. Whey protein supplementation may increase the effects of exercise on strength and muscle mass, in addition to promoting improved endothelial function, body composition and quality of life. However, studies are needed to evaluate its benefits in patients with HF.

Methods/design: This is a double-blind, randomized, placebo-controlled clinical trial in which patients with HF will be randomly allocated to two groups to receive supplementation with whey protein or placebo, associated with supervised exercise, for 12 weeks. The frequency of exercise will be three times a week. The study variables will be evaluated at baseline and 12 weeks. The main outcome will be maintenance of muscle mass and strength. Microvascular reactivity, quality of life, and inflammatory parameters will be evaluated as secondary outcomes.

Discussion: HF is associated with severe loss of muscle mass and strength, directly contributing to exercise intolerance and inability to maintain daily life activities, becoming a strong predictor of reduced quality of life and mortality. The results of this study will add to the evidence base for providing new dietary recommendations.

Trial registration: ClinicalTrials.gov, ID: NCT03142399. Registered on 29 May 2016. Effect of Whey Protein' Supplementation and Exercise in Patients with Heart Failure (PROT-HF).
\end{abstract}

Keywords: Heart failure, Cardiac rehabilitation, Randomized controlled trial, Study design, Whey proteins

\section{Background}

Heart failure (HF) is a clinical syndrome associated with poor quality of life, high utilization of economic resources, largely related to high hospitalization rates, and is a major cause of mortality worldwide [1-3].

Loss of muscle mass is a serious complication that affects a large proportion of patients with HF $[4,5]$, causing an impact on the physical capacity, quality of life, and survival of

\footnotetext{
* Correspondence: elisamaia80@gmail.com

${ }^{1}$ Institute of the Heart Edson Saad, Federal University of Rio de Janeiro (UFRJ), Rio de Janeiro, RJ, Brazil

${ }^{7}$ Department of Clinical Research, National Institute of Cardiology (INC), Rua das Laranjeiras, 374, 50 andar - Laranjeiras, Rio de Janeiro, RJ CEP: 22240-006, Brazil

Full list of author information is available at the end of the article
}

these patients. The impairment of cardiac muscle function leads to numerous neurohormonal and metabolic disorders, including an imbalance between anabolic and catabolic processes [6], being a complex scenario in which drug treatments are not available. Two distinct conditions that may be present in this group of patients, and are characterized by loss of skeletal muscle mass, are sarcopenia and cachexia.

Cachexia is a complex syndrome characterized by severe and involuntary muscle mass loss, associated or not with loss of adipose tissue. It is common in chronic diseases, such as cancer and HF, and may even occur in the absence of chronic diseases, since sarcopenia represents a slow and progressive muscle mass loss which comes with aging [7]. The prevalence of sarcopenia varies according to age 
groups representing 1-2\% per year after 50 years, $15 \%$ at 65 years, and $50 \%$ at 80 years [8].

Regardless of its causes or mechanisms, loss of muscle mass directly contributes to exercise intolerance and impairment of daily life activities, becoming a strong predictor of reduced quality of life and mortality [9-11].

Physical exercise has been shown to be a non-pharmacological, effective, low-cost, and safe therapy that can aid in the treatment of HF, inducing anabolism through the activation or deactivation of molecular pathways essential for muscle synthesis, improving physical capacity and increasing lean mass in those patients with previous depletion [12-15]. Cardiac rehabilitation programs in patients with HF reduce mortality and hospitalization rates and improve functional ability, duration of exercise, and quality of life $[16,17]$.

It is well established that food consumption is a strong stimulator of muscle protein synthesis $[18,19]$. Intake of protein-rich meals in the form of free amino acids [20], milk protein [21], or meat [22] is able to stimulate muscle protein synthesis. This response depends on the amount, and also on the type of protein that is ingested [23]. Whey protein (WP) is a high-quality protein that has shown superiority in enhancing muscle protein synthesis compared with other protein sources in older adults, it is rapidly digested and has a high concentration of leucine [24] that plays an important role in the stimulation of postprandial muscle protein synthesis [25]. Leucine is one of the essential amino acids in the diet. It is capable, like all branched-chain amino acids, of avoiding hepatic alterations due to the lack of L-branched chain aminotransferase in the liver and its ingestion reportedly activates the mTOR pathway in skeletal muscle, contributing to a hypertrophy response [26].

Whey protein has already demonstrated a positive effect on protein synthesis and muscle mass gain [27] when associated with exercise $[28,29]$, but there are no studies in the academic literature that evaluate its benefits in patients with HF.

Currently, the most promising approach to treat depletion of nutritional status due to the disease appears to be a combination therapy that includes exercise, nutritional counseling, and drug therapy [4, 30], helping to manage symptoms, reducing the number of readmissions, and improving life quality [31].

Thus, the main objective of this study will be to evaluate whether supplementation with WP alone in association with 12-week supervised exercise will be able to preserve muscle mass in patients with New York Heart Association (NYHA) functional class I or II HF. As secondary objectives, an increase in muscle strength, an improvement in endothelial function assessed through microvascular reactivity, improvement in quality of life, and reduction of inflammatory markers will be evaluated.

\section{Methods/design}

\section{Study design and interventions}

This is a double-blind, randomized, placebo-controlled clinical trial in which participants will be followed-up for a 12-week intervention period in which they will undergo supervised exercise through cardiac rehabilitation program participation. Participants will randomly be allocated into two groups to receive supplementation with WP alone or placebo and outcomes will be measured at baseline and upon completion of 12 weeks of study.

For the intervention group will be the supplementation of WP isolate at an amount of $30 \mathrm{~g}$ per day, totaling $27 \mathrm{~g}$ of protein and $120 \mathrm{kcal}$ per serving. For the placebo group, maltodextrin will be given at an amount of $30 \mathrm{~g}$ per day, totaling $30 \mathrm{~g}$ of carbohydrates and $120 \mathrm{kcal}$ per serving.

Patients will be instructed to consume supplements daily for 12 weeks, and consumption will be performed immediately after the training session on days of cardiac rehabilitation and on days without training, consumption will be performed at a time defined by the patient.

The study protocol complies with the Standard Protocol Items: Recommendations for Clinical Trials (SPIRIT) guidelines.

\section{Setting}

The study will occur at the National Institute of Cardiology in Rio de Janeiro, Brazil, a reference unit in tertiary-level cardiology treatment linked to the Brazilian Ministry of Health.

\section{Participants}

Patients with a clinical diagnosis of HF, with NYHA functional class I or II, and who have been referred for cardiac rehabilitation by their attending physicians, will be assessed.

\section{Inclusion criteria}

Age $\geq 50$ years

Heart failure functional class I or II NYHA

Clinical stability (symptoms and medication) for more

than 4 weeks

Ejection fraction $\leq 50 \%$

\section{Exclusion criteria}

Creatinine clearance $<50 \mathrm{ml} / \min / 1.73 \mathrm{~m}^{2}$, impaired hepatic function (alanine aminotransferase $>150 \mathrm{U} / \mathrm{l}$ ) or decompensated hepatic cirrhosis classified as Child-Pugh grade $\mathrm{B}$ or $\mathrm{C}$, atrial fibrillation with heart rate $>100 \mathrm{bpm}$, allergies to milk proteins, and any osteoarticular impediment preventing physical exercise. 


\section{Additional exclusion criteria}

After the initial medical consultation, patients who are unable to understand and perform the study procedures will be excluded.

During the exercise protocol, participants will be under medical supervision to reduce any health risk, and those with decompensated heart disease will be referred to the emergency room of the hospital where the study will be conducted.

\section{Endpoints}

The main outcome will be maintenance of muscle mass and strength. Microvascular reactivity, quality of life, and inflammatory parameters will be evaluated as secondary outcomes.

\section{Study procedures}

Figure 1 describes all the study steps, from patient recruitment to intervention. Patients will be pre-selected from the waiting list for participation in the cardiac rehabilitation (CR) program. The waiting list consists of patients with HF who were referred to the CR program by their assisting physicians and are waiting to be scheduled. Telephone contact will be made with patients meeting the inclusion criteria, who will be scheduled for consultation with a cardiologist. During consultation, the inclusion criteria will be checked, and the informed consent will be signed. Finally, patients will be randomized and allocated to a study group.

The procedures performed at the beginning of the study will be a cardiopulmonary exercise test (CPET), echocardiogram, microvascular reactivity test, blood collection for biochemical evaluation, handgrip-strength assessment, anthropometric and body composition evaluation, health-related quality of life assessment, and assessment of dietary intake. All initial evaluations will be repeated at 12 weeks.

All staff will be trained in the operation of the equipment for data collection and obtaining written informed

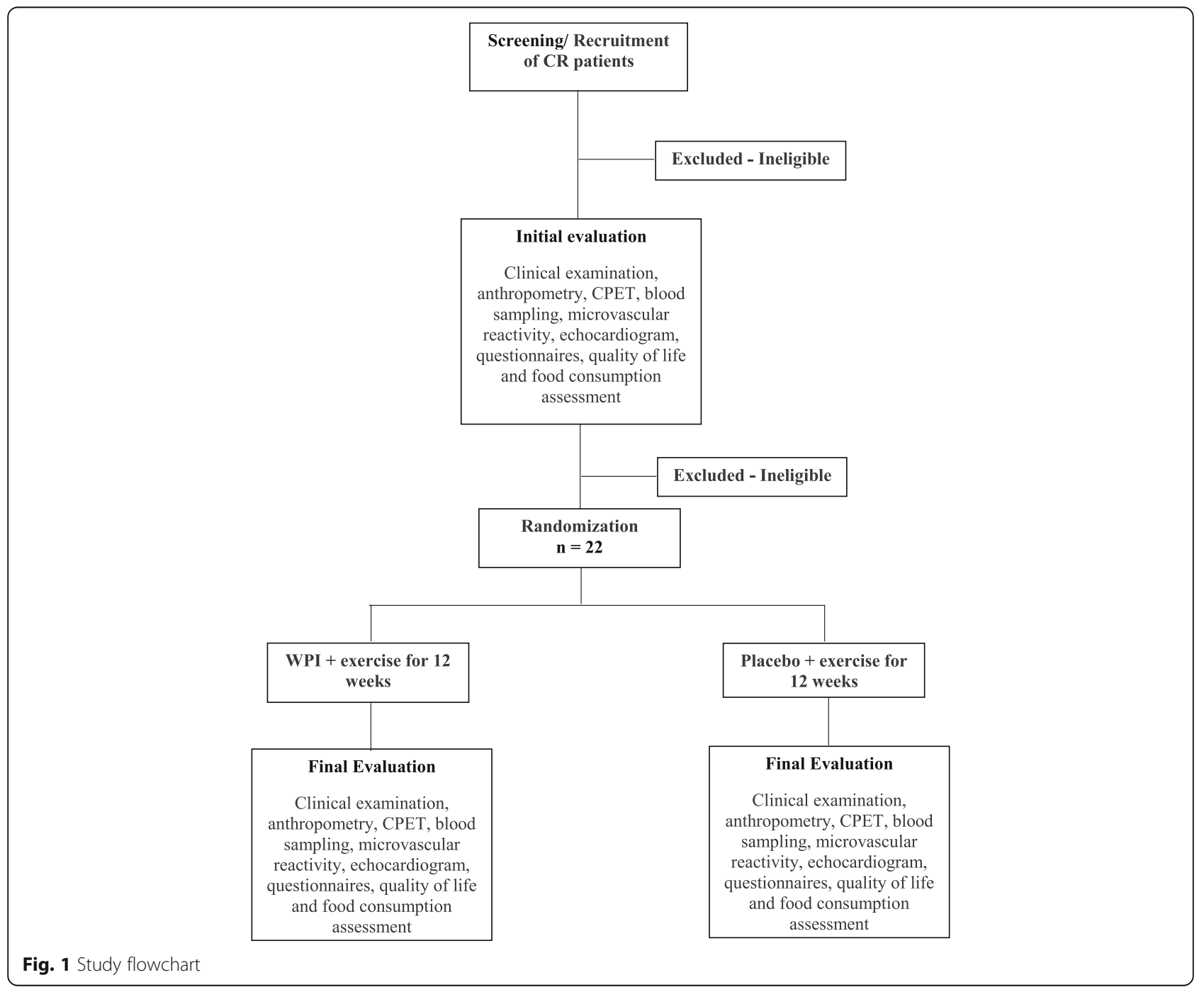


consent. Additionally all members of the research team will participate in the work meetings to periodically evaluate the quality of the information collected, in order to minimize errors and ensure the reliability of the data. All the research team will be trained every 6 months during the research period.

Participants will receive a weekly structured telephone interview, with questions addressing side effects (mainly gastrointestinal), symptoms, adherence, and difficulties in carrying out the guidelines provided during the study.

\section{Randomization and blinding}

Randomization will occur in blocks of 2 and will be based on a table of random numbers generated in the online open program Openepi [32]. The random number table will be confidential. The packaging and distribution of the supplements will be performed by personnel not involved in the research. All researchers directly involved in the care and follow-up of the participating patients will not be aware of the supplements taken by the study patients. Unblinding may occur if requested by the assisting physician if a patient suffers clinical destabilization. The supplements will be delivered to the patients in metalized packages, sealed and identified by the name and code of the patient in the study, and it is not possible to identify the supplement as placebo or WP.

\section{Sample size}

Considering a muscle mass gain of $500 \mathrm{~g}$ in the intervention group at 12 weeks compared to the placebo group, with a standard deviation (SD) of $409.7 \mathrm{~g}, 11 \mathrm{pa}-$ tients in each group are required to guarantee $95 \%$ confidence and $80 \%$ power to the study. The results obtained in a similar study with WP supplementation were used as a reference [33].

\section{Collection and storage of blood}

Blood collection will be performed after $12 \mathrm{~h}$ of fasting. Complete blood count, fasting glucose, glycated hemoglobin, serum lipids, liver enzymes, urea, creatinine, uric acid, thyroid hormones, fibrinogen, and C-reactive protein will be analyzed.

\section{Nutritional assessment}

Nutritional assessment will consist of anthropometric and body composition evaluations. The anthropometric evaluation will include body mass, height, and Body Mass Index calculation, waist, hip, neck, and calf-girth measurements, as well as triceps, subscapular, and calf skinfolds. All measurements will be made in duplicate and the average values obtained will be used.

For the evaluation of body composition, a tetrapolar eight-point tactile electrode system will be used, which separately measures impedance of the subject's trunk, arms, and legs at six different frequencies $(1 \mathrm{kHz}, 5 \mathrm{kHz}$, $50 \mathrm{kHz}, 250 \mathrm{kHz}, 500 \mathrm{kHz}, 1000 \mathrm{kHz}$ ) for each of the body segments. The spectrum of electrical frequencies will be used to predict the intracellular water (ICW) and extracellular water (ECW) compartments of the total body water (TBW) in the various body segments (Inbody $720^{\circ}$, Bioespace Co. Ltd., Seoul, South Korea). The body composition analyzer has in-built hand and foot electrodes. Subjects will wear normal indoor clothing and be advised to stand barefoot in an upright position with their feet on the foot electrodes on the machine platform and their arms abducted with hands gripping on to the hand electrodes on the handles. Subjects are require to fast for the test [34].

\section{Nutritional counseling}

Patients will receive individualized nutritional counseling according to the treatment guidelines for HF in order to achieve adequate weight. There will be monthly consultations with a nutritionist, in which specific nutritional guidelines for each patient will be considered, according to weight, age, and gender, with calculation of caloric and protein intake and food planning.

During consultations, patients will receive supplements in individual packs labeled with name, study identification code and dose number, containing $30 \mathrm{~g}$ of the supplement for 4 weeks of supplementation. Patients will be advised on how to prepare the supplement and on its ingestion schedule. Each patient is expected to return the empty packages at each visit as a form of control of the supplement consumption and will be instructed not to consume other nutritional supplements during the study.

\section{Food consumption}

Twenty-four-hour food recall will be assessed in all consultations with nutritionists. Food records will be made for 3 days a month, on two working days (one common day and 1 day with Cardiac Rehabilitation program) and one weekend day. Patients will be advised not to perform the records on consecutive days. The Food Processor program (ESHA, Salem, OR, USA) will be used to evaluate macro and micronutrient consumption.

\section{Quality of life}

Quality of life will be assessed using the validated Brazilian version of the Minnesota Living with Heart Failure Questionnaire (MLHFQ) [35]. The questionnaire will be applied at times $\mathrm{T} 0$ and $\mathrm{T} 12$.

\section{Muscle strength}

The evaluation of muscle strength will be performed monthly by means of the measurement of the handgrip 
force using the Jamar ${ }^{\circledR}$ brand hand-held dynamometer [36]. Participants will remain seated in a standard-height chair, with a neutral adducted and rotated shoulder, elbow flexed at $90^{\circ}$, forearm in neutral position, wrist in dorsiflexion of $0-30^{\circ}$ and ulnar deviation of $0-15^{\circ}$. The dynamometer will be adjusted based on the participant's hand size for optimum grip position. The test will be conducted with standard verbal instructions (such as, "one, two, three, tighten ... stronger ...") and participants will be instructed to use the non-dominant hand first, followed by the dominant hand. Three measurements will be taken for each hand, with a 10-20 s rest interval between measures to avoid fatigue. The average value of the three measures will be used [37, 38].

\section{Functional capacity}

All patients will undergo a symptom-limited CPET, performed on a treadmill (Ergo PC Elite, Micromed, Brasilia, Brazil) with a ramp protocol. Heart rate and blood pressure will be measured every minute during exercise and recovery. A 12-lead electrocardiogram (ECG) will be continuously evaluated and will also be recorded every $3 \mathrm{~min}$. After calibration of the volumes and gas exchange analyzers, patients will breathe through a mask connected to a two-way respiratory valve. Expired gases and volumes will be analyzed $\left(\mathrm{VO}_{2000}\right.$, MedGraphics, St. Paul, $\mathrm{MN}$, USA) [39].

\section{Echocardiogram}

Conventional echocardiography will be performed in all patients using standard views, with the patient in the left lateral decubitus position, using a commercially available ultrasound machine (Vivid E9, GE Healthcare, Horten, Norway). Echocardiographic images will be obtained by a single experienced examiner and recorded for a second analysis by another experienced observer. Both will be blinded to patient allocation. Left ventricular ejection fraction (LVEF) will be calculated using the Simpson method, and all other parameters will be obtained and analyzed in accordance with the criteria defined on EAE/ASE/EACI guidelines [40, 41].

\section{Exercise training protocol}

The exercise program will consist of supervised aerobic and strength exercises, three times a week for 12 weeks. Aerobic training will occur before strength training and will start with a 7 -min warm-up at $40 \%$ of the maximal functional capacity (MFC) obtained from baseline CPET, ending with a cooling-down of $3 \mathrm{~min}$ at $30 \%$ of MFC (Table 1).

Once a week, patients will undergo a continuous exercise training protocol consisting of $30 \mathrm{~min}$ at $60-70 \%$ of MFC. Training intensity will be controlled using a heart rate monitor and the Borg Scale score aiming at levels 12-14 during the training session, as recommended in the current exercise guidelines for $\mathrm{HF}$ patients [16]. Twice a week, a high-intensity interval training protocol will be performed, with eight sets of $40 \mathrm{~s}$ at $90-95 \%$ of MFC separated by $110 \mathrm{~s}$ of moderate-intensity exercise at $50 \%$ of MFC. Workload will be increased during the 12-week training period based on the Borg Scale of perceived effort. The Borg Scale score and heart rate will be determined after warm-up, at 20,30, and $40 \mathrm{~min}$ of exercise, and after cooling down.

Strength training will be implemented three times a week after aerobic exercise sections and will consist of eight dynamic strength exercises for larger muscles (quadriceps (2), hip (2), trunk (2), dorsal (1), and pectoral (1)) with three sets of 10 repetitions at near-maximal load separated by 1-min rest intervals between sets. During strength training, heart rate, and blood pressure will be monitored at 10-min intervals, and the load will be increased progressively once the patients can successfully perform three sets of 10 repetitions. Participants will be instructed not to perform any other exercise during the study.

\section{Microvascular reactivity}

A laser speckle contrast imaging system with a laser wavelength of $785 \mathrm{~nm}$ (PeriCam PSI system, Perimed, Järfälla, Sweden) coupled to iontophoresis of acetylcholine and sodium nitroprusside will measure non-invasively real-time cutaneous microvascular flow changes in the forearm [42]. For the post-occlusive reactive hyperemia (PORH) test,

Table 1 Exercise training, prescription, and monitoring of patients on the cardiac rehabilitation program

\begin{tabular}{|c|c|c|c|c|c|}
\hline Type of exercise & & Intensity of exercise & $\begin{array}{l}\text { Duration of } \\
\text { sessions }\end{array}$ & Monitoring & $\begin{array}{l}\text { Weekly } \\
\text { frequency }\end{array}$ \\
\hline $\begin{array}{l}\text { Continuous } \\
\text { exercise }\end{array}$ & $\begin{array}{l}\text { Aerobic training } \\
\text { (walking) }\end{array}$ & $60-70 \% \mathrm{VO}_{2} \max$ & $30 \mathrm{~min}$ & $\begin{array}{l}\text { BS (levels 12-14), BP, } \\
\text { ECG and HR }\end{array}$ & Once a week \\
\hline $\begin{array}{l}\text { High-intensity } \\
\text { interval training }\end{array}$ & $\begin{array}{l}\text { Aerobic training } \\
\text { (walking) }\end{array}$ & $\begin{array}{l}8 \text { sets of } 40 \mathrm{~s} \text { at } 90-95 \% \mathrm{VO}_{2} \text { max } \\
\text { separated by } 110 \mathrm{~s} \text { of } \\
\text { moderate-intensity exercise } \\
\text { at } 50 \% \mathrm{VO}_{2} \max \end{array}$ & $\begin{array}{l}\text { Approximately } \\
20 \text { min }\end{array}$ & $\begin{array}{l}\text { BS (levels 12-14), BP, } \\
\text { ECG and HR }\end{array}$ & Twice a week \\
\hline $\begin{array}{l}\text { Strength } \\
\text { training }\end{array}$ & $\begin{array}{l}\text { Dynamic with machine } \\
\text { weights (quadriceps, hip, } \\
\text { trunk, dorsal and pectoral) }\end{array}$ & $\begin{array}{l}3 \text { sets of } 10 \text { repetitions } \\
\text { (30-40\% of body weight) }\end{array}$ & $\begin{array}{l}\text { Approximately } \\
30 \text { min }\end{array}$ & $\begin{array}{l}\text { Symptom-limited exercise } \\
\text { test with } \mathrm{HR} \text { and BP will be } \\
\text { monitored at } 10 \text {-min intervals }\end{array}$ & 3 times a week \\
\hline
\end{tabular}


arterial occlusion will be performed with suprasystolic pressure $(50 \mathrm{mmHg}$ above the systolic arterial pressure) using a sphygmomanometer applied to the arm of the subject over 3 min. Peak skin flow will be measured after pressure release.

Images will be analyzed using the manufacturer's software (PIMSoft, Perimed, Järfälla, Sweden). The measurements of skin blood flow will be divided by the mean arterial pressure to yield the cutaneous vascular conductance (CVC) in arbitrary perfusion units (APU)/ $\mathrm{mmHg}$, to avoid interference of blood pressure levels on calculation of microvascular flow.

\section{Statistical analysis}

Categorical variables will be presented as frequencies with percentages and will be compared using Fisher's exact test and the chi-square test. Continuous variables will be presented as mean \pm SD or median and interquartile range and will be compared using two-way analysis of variance (ANOVA) or Friedman's test, whenever appropriate. A logistic regression analysis will be used to identify variables with an independent association with increase of lean muscle mass. A value of $p<0.05$ will be considered statistically significant in all analyses. Calculations will be performed using the Statistical Package for the Social Sciences (SPSS 21.0 for Windows) program.

\section{Ethics and dissemination}

The study was submitted and approved by the Ethics and Research Committee of the National Institute of Cardiology, in Rio de Janeiro, Brazil and the participants will sign the free and informed consent form. Any modifications that are made to the study will be immediately reported to the Ethics Committee responsible for approving the trial. A Data Monitoring Committee (DMC) will not be needed as this is a single-center trial. To ensure the confidentiality and the safety of participants, all information about participants will be stored safely in a computer with access restricted to the study's investigators and, if any harm occurs, patients will have full access to free treatment at the National Institute of Cardiology, which belongs to the Brazilian public healthcare system.

\begin{tabular}{|c|c|c|c|c|c|c|c|c|c|c|c|c|c|c|}
\hline & \multicolumn{14}{|c|}{ STUDY PERIOD } \\
\hline & \multirow{2}{*}{$\begin{array}{c}\text { Enrolment } \\
-t_{1}\end{array}$} & \multirow{2}{*}{$\begin{array}{c}\text { Allocation } \\
\text { t0 }\end{array}$} & \multicolumn{11}{|c|}{ Post-allocation } & \multirow{2}{*}{$\begin{array}{c}\text { Close-out } \\
t_{12}\end{array}$} \\
\hline TIMEPOINT & & & $t 1$ & 12 & $t 3$ & $t 4$ & $t 5$ & $t 6$ & $t 7$ & $t 8$ & $t 9$ & $\begin{array}{c}t \\
10\end{array}$ & $\stackrel{t}{11}$ & \\
\hline ENROLMENT: & & & & & & & & & & & & & & \\
\hline Eligibility screen & $\mathrm{X}$ & & & & & & & & & & & & & \\
\hline Informed consent & $\mathrm{X}$ & & & & & & & & & & & & & \\
\hline Clinical examination & $\mathrm{X}$ & & & & & & & & & & & & & \\
\hline Blood biomarkers & $\mathrm{X}$ & & & & & & & & & & & & & $\mathrm{X}$ \\
\hline Allocation & & $\mathrm{X}$ & & & & & & & & & & & & \\
\hline INTERVENTIONS: & & & & & & & & & & & & & & \\
\hline WP supplementation & & $\leftarrow$ & & & & & & & & & & & & $\rightarrow$ \\
\hline Exercise training & & $\leftarrow$ & & & & & & & & & & & & $\longrightarrow$ \\
\hline ASSESSMENTS: & & & & & & & & & & & & & & \\
\hline Muscle mass & $\mathrm{X}$ & $\mathrm{X}$ & & & & $\mathrm{X}$ & & & & $\mathrm{X}$ & & & & $\mathrm{X}$ \\
\hline CPET & $\mathrm{X}$ & & & & & & & & & & & & & $\mathrm{X}$ \\
\hline Hand grip force & & $\mathrm{X}$ & & & & $\mathrm{X}$ & & & & $\mathrm{X}$ & & & & $\mathrm{X}$ \\
\hline Echocardiogram & $\mathrm{X}$ & & & & & & & & & & & & & $\mathrm{X}$ \\
\hline Microvascular reactivity & & $\mathrm{X}$ & & & & & & & & & & & & $\mathrm{X}$ \\
\hline Nutritional assessment & $\mathrm{X}$ & $\mathrm{X}$ & & & & $\mathrm{X}$ & & & & $\mathrm{X}$ & & & & $\mathrm{X}$ \\
\hline 3-day Food record & & $\mathrm{X}$ & & & & $\mathrm{X}$ & & & & $\mathrm{X}$ & & & & $\mathrm{X}$ \\
\hline$M L H F Q$ & & $\mathrm{X}$ & & & & $\mathrm{X}$ & & & & $\mathrm{X}$ & & & & $\mathrm{X}$ \\
\hline
\end{tabular}

Fig. 2 Standard Protocol Items: Recommendation for Interventional Trials (SPIRIT): the schedule of enrollment, interventions, and assessments 
Throughout the trial, the partial results will be presented at national and international scientific congresses. This study will contribute significantly to the academic training of health professionals in the area of cardiovascular sciences, committed to the production of knowledge and critical reflection, and generate new interventions capable of optimizing the treatment and quality of life of patients with HF. At the end of the study the results of the study will be published in scientific journals and presented at scientific meetings.

\section{SPIRIT}

This protocol has been written in accordance with the Standard Protocol Items: Recommendations for Interventional Trials (SPIRIT) guidelines. The SPIRIT Checklist is in Additional file 1. The SPIRIT Figure is in Fig. 2.

\section{Discussion}

The proposed study is a double-blind, randomized, placebo-controlled clinical trial aimed at investigating the effects of WP supplementation associated with 12 weeks of supervised exercise in maintaining muscle strength in patients with HF. Advanced HF is often associated with severe loss of body weight and especially of muscle mass, and it is an important cause of hospitalization and one of the most important health challenges since its prevalence tends to increase with the aging of the population and the increase in the survival of patients who have suffered acute coronary events. It is an ongoing epidemic problem, resulting in a high socioeconomic cost, represented by the expenditure on medicines, repeated hospitalizations, loss of productivity, early retirement, possible surgeries and, ultimately, the need for heart transplantation. In this sense, it is of great importance to carry out studies that evaluate the possible benefits of new clinical and nutritional interventions for HF patients, favoring the development of new treatment strategies.

\section{Trial status}

Patient recruitment is currently being undertaken.

\section{Additional file}

Additional file 1: Standard Protocol Items: Recommendations for Interventional Trials (SPIRIT)_guidelines_WPROT_HF. (PDF 208 kb)

\footnotetext{
Abbreviations

APU: Arbitrary perfusion units; CPET: Cardiopulmonary exercise test; CR: Cardiac rehabilitation; CVC: Cutaneous vascular conductance; DMC: Data Monitoring Committee; ECG: Electrocardiogram; ECW: Extracellular water; HF: Heart failure; ICW: Intracellular water; LVEF: Left ventricular ejection fraction; MFC: Maximal functional capacity; MLHFQ: Minnesota Living with Heart Failure Questionnaire; NYHA: New York Heart Association; PORH: Postocclusive reactive hyperemia; SPSS: Statistical Package for the Social Sciences; TBW: Total body water; WP: Whey protein
}

\section{Acknowledgements}

The authors thank Marcio Marinho Gonzalez and Mariana Garcia Fernandes da Silva for technical assistance, and Marcelo Correia for statistical assistance.

\section{Funding}

This study will be funded by the National Institute of Cardiology (Brazilian Ministry of Health) and Fundação PróCoração (FUNDACOR).

\section{Availability of data and materials}

The datasets used and analyzed during the current study are available from the corresponding author on reasonable request.

\section{Authors' contributions}

EMS, ASBM, and ARL are responsible for the trial, leading on protocol writing, ethics application and manuscript preparation. GVBH is responsible for randomization of patients and distribution of supplements. EMS, RM, EVT, GVBH, ASBM, and ARL contributed fully to study design. All authors read and approved the final manuscript.

\section{Authors' information}

Elisa Maia dos Santos, MS is a dietitian in the Instituto Nacional de Cardiologia and a PhD student at Universidade Federal do Rio de Janeiro, Rio de Janeiro, RJ, Brazil; Roger de Moraes, PhD is a professor and researcher at the Universidade Estácio de Sá, Rio de Janeiro, RJ, Brazil; Eduardo Vera Tibiriça, $\mathrm{PhD}$ is a professor and researcher at the Instituto Nacional de Cardiologia and Fundação Oswaldo Cruz, Rio de Janeiro, RJ, Brazil; Grazielle Vilas Bôas Huguenin, PhD is a professor and researcher at the Universidade Federal Fluminense, Niterói, Brazil and Instituto Nacional de Cardiologia, Rio de Janeiro, RJ, Brazil; Annie Seixas Belo Moreira, PhD is a professor and researcher at the Universidade do Estado do Rio de Janeiro, Rio de Janeiro, RJ, Brazil; Andrea Rocha De Lorenzo, PhD is a professor and researcher at the Instituto Nacional de Cardiologia and Universidade Federal do Rio de Janeiro.

Ethics approval and consent to participate

Ethical approval was obtained from the Ethics and Research Committee of the National Institute of Cardiology, in Rio de Janeiro, Brazil and the participants will sign the free and informed consent form.

\section{Consent for publication}

We have gained informed consent for publication of the dataset from patients at the point of recruitment to the trial. All the patient details will be fully anonymous.

\section{Competing interests}

The authors declare that they have no competing interests.

\section{Publisher's Note}

Springer Nature remains neutral with regard to jurisdictional claims in published maps and institutional affiliations.

\section{Author details}

${ }^{1}$ Institute of the Heart Edson Saad, Federal University of Rio de Janeiro (UFRJ), Rio de Janeiro, RJ, Brazil. ²Universidade Estácio de Sá, Rio de Janeiro, RJ, Brazil. ${ }^{3}$ Laboratory of Cardiovascular Investigation, Oswaldo Cruz Institute (IOC), Rio de Janeiro, RJ, Brazil. ${ }^{4}$ Universidade Federal Fluminense (UFF), Niterói, Brazil. ${ }^{5}$ National Institute of Cardiology (INC), Rio de Janeiro, RJ, Brazil. ${ }^{6}$ State University of Rio de Janeiro, Rio de Janeiro, RJ, Brazil. " Department of Clinical Research, National Institute of Cardiology (INC), Rua das Laranjeiras, 374, 50 andar - Laranjeiras, Rio de Janeiro, RJ CEP: 22240-006, Brazil.

Received: 10 December 2017 Accepted: 17 July 2018

Published online: 08 August 2018

\section{References}

1. Ponikowski P, Voors AA, Anker SD, Bueno H, Cleland JGF, Coats AJS, et al. 2016 ESC guidelines for the diagnosis and treatment of acute and chronic heart failure: The Task Force for the diagnosis and treatment of acute and chronic heart failure of the European Society of Cardiology (ESC). Developed with the special contribution of the heart failure association (HFA) of the ESC. Eur J Heart Fail. 2016;18(8):891-975. 
2. Heidenreich PA, Albert NM, Allen LA, Bluemke DA, Butler J, Fonarow GC, et al. Forecasting the impact of heart failure in the United States: a policy statement from the American Heart Association. Circ Heart Fail. 2013;6(3):606-19.

3. McMurray JJJV. Improving outcomes in heart failure: a personal perspective. Eur Heart J. 2015;36(48):3467-70.

4. von Haehling S, Ebner N, Dos Santos MR, Springer J, Anker SD. Muscle wasting and cachexia in heart failure: mechanisms and therapies. Nat Rev Cardiol. 2017;14(6):323-41.

5. Bekfani T, Pellicori P, Morris DA, Ebner N, Valentova M, Steinbeck L, et al. Sarcopenia in patients with heart failure with preserved ejection fraction: impact on muscle strength, exercise capacity and quality of life. Int J Cardiol. 2016;222:41-6.

6. Josiak K, Jankowska EA, Piepoli MF, Banasiak W, Ponikowski P. Skeletal myopathy in patients with chronic heart failure: significance of anabolic androgenic hormones. J Cachexia Sarcopenia Muscle. 2014;5(4):287-96.

7. Bowen TS, Schuler G, Adams V. Skeletal muscle wasting in cachexia and sarcopenia: molecular pathophysiology and impact of exercise training. J Cachexia Sarcopenia Muscle. 2015;6(3):197-207.

8. Kim TN, Choi KM. Sarcopenia: definition, epidemiology, and pathophysiology. J Bone Metab. 2013;20(1):1-10.

9. Zhou X, Wang JL, Lu J, Song Y, Kwak KS, Jiao Q, et al. Reversal of cancer cachexia and muscle wasting by ActRIIB antagonism leads to prolonged survival. Cell. 2010;142(4):531-43.

10. Saitoh M, Dos Santos MR, Ebner N, Emami A, Konishi M, Ishida J, et al. Nutritional status and its effects on muscle wasting in patients with chronic heart failure: insights from studies investigating co-morbidities aggravating heart failure. Wien Klin Wochenschr. 2016;128(Suppl 7):497-504.

11. Anker SD, Ponikowski P, Varney S, Chua TP, Clark AL, Webb-Peploe KM, et al Wasting as independent risk factor for mortality in chronic heart failure. Lancet Lond Engl. 1997;349(9058):1050-3.

12. Gielen S, Sandri M, Kozarez I, Kratzsch J, Teupser D, Thiery J, et al. Exercise training attenuates MuRF-1 expression in the skeletal muscle of patients with chronic heart failure independent of age: the randomized Leipzig Exercise Intervention in Chronic Heart Failure and Aging Catabolism study. Circulation. 2012;125(22):2716-27

13. O'Connor CM, Whellan DJ, Lee KL, Keteyian SJ, Cooper LS, Ellis SJ, et al. Efficacy and safety of exercise training in patients with chronic heart failure: HF-ACTION randomized controlled trial. JAMA. 2009;301(14):1439-50.

14. Sandri M, Kozarez I, Adams V, Mangner N, Höllriegel R, Erbs S, et al. Agerelated effects of exercise training on diastolic function in heart failure with reduced ejection fraction: the Leipzig Exercise Intervention in Chronic Heart Failure and Aging (LEICA) Diastolic Dysfunction study. Eur Heart J. 2012; 33(14):1758-68.

15. Lenk K, Erbs S, Höllriegel R, Beck E, Linke A, Gielen S, et al. Exercise training leads to a reduction of elevated myostatin levels in patients with chronic heart failure. Eur J Prev Cardiol. 2012;19(3):404-11.

16. Piepoli MF, Conraads V, Corrà U, Dickstein K, Francis DP, Jaarsma T, et al. Exercise training in heart failure: from theory to practice. a consensus document of the Heart Failure Association and the European Association for Cardiovascular Prevention and Rehabilitation. Eur J Heart Fail. 2011;13(4):347-57.

17. Piepoli MF, Davos C, Francis DP, Coats AJS, ExTraMATCH Collaborative. Exercise training meta-analysis of trials in patients with chronic heart failure (ExTraMATCH). BMJ. 2004:328(7433):189.

18. Bohé J, Low A, Wolfe RR, Rennie MJ. Human muscle protein synthesis is modulated by extracellular, not intramuscular amino acid availability: a dose-response study. J Physiol. 2003;552(Pt 1):315-24.

19. Moore DR, Tang JE, Burd NA, Rerecich T, Tarnopolsky MA, Phillips SM. Differential stimulation of myofibrillar and sarcoplasmic protein synthesis with protein ingestion at rest and after resistance exercise. J Physiol. 2009; 587(Pt 4):897-904

20. Volpi E, Kobayashi H, Sheffield-Moore M, Mittendorfer B, Wolfe RR. Essentia amino acids are primarily responsible for the amino acid stimulation of muscle protein anabolism in healthy elderly adults. Am J Clin Nutr. 2003, 78(2):250-8.

21. Koopman R, Walrand S, Beelen M, Gijsen AP, Kies AK, Boirie Y, et al. Dietary protein digestion and absorption rates and the subsequent postprandial muscle protein synthetic response do not differ between young and elderly men. J Nutr. 2009;139(9):1707-13.

22. Symons TB, Schutzler SE, Cocke TL, Chinkes DL, Wolfe RR, Paddon-Jones D. Aging does not impair the anabolic response to a protein-rich meal. Am J Clin Nutr. 2007:86(2):451-6
23. Tang JE, Phillips SM. Maximizing muscle protein anabolism: the role of protein quality. Curr Opin Clin Nutr Metab Care. 2009;12(1):66-71.

24. Dangin M, Boirie Y, Garcia-Rodenas C, Gachon P, Fauquant J, Callier P, et al. The digestion rate of protein is an independent regulating factor of postprandial protein retention. Am J Physiol Endocrinol Metab. 2001;280(2):E340-8.

25. Koopman R, Wagenmakers AJM, Manders RJF, Zorenc AHG, Senden JMG, Gorselink M, et al. Combined ingestion of protein and free leucine with carbohydrate increases postexercise muscle protein synthesis in vivo in male subjects. Am J Physiol Endocrinol Metab. 2005;288(4):E645-53.

26. Lane M, Herda T, Fry A, Cooper M, Andre M, Gallagher P. Endocrine responses and acute mTOR pathway phosphorylation to resistance exercise with leucine and whey. Biol Sport. 2017;34(2):197-203.

27. Pennings B, Boirie $Y$, Senden JMG, Gijsen AP, Kuipers H, van Loon LJC. Whey protein stimulates postprandial muscle protein accretion more effectively than do casein and casein hydrolysate in older men. Am J Clin Nutr. 2011; 93(5):997-1005.

28. Chalé A, Cloutier GJ, Hau C, Phillips EM, Dallal GE, Fielding RA. Efficacy of whey protein supplementation on resistance exercise-induced changes in lean mass, muscle strength, and physical function in mobility-limited older adults. J Gerontol A Biol Sci Med Sci. 2013;68(6):682-90.

29. Verreijen AM, Verlaan S, Engberink MF, Swinkels S, de Vogel-van den Bosch J. Weijs PJM. A high whey protein-, leucine-, and vitamin D-enriched supplement preserves muscle mass during intentional weight loss in obese older adults: a double-blind randomized controlled trial. Am J Clin Nutr. 2015;101(2):279-86.

30. Saitoh M, Ishida J, Doehner W, von Haehling S, Anker MS, Coats AJS, et al. Sarcopenia, cachexia, and muscle performance in heart failure: review update 2016. Int J Cardiol. 2017;238:5-11.

31. Lourenço BH, Vieira LP, Macedo A, Nakasato M, Marucci Mde FN, Bocchi EA. Nutritional status and adequacy of energy and nutrient intakes among heart failure patients. Arq Bras Cardiol. 2009;93(5):541-8.

32. OpenEpi - Toolkit Shell for Developing New Applications [Internet]. Accessed 5 Jun 2017. Available from: http://www.openepi.com/Random/ Random.htm.

33. Rondanelli M, Klersy C, Terracol G, Talluri J, Maugeri R, Guido D, et al. Whey protein, amino acids, and vitamin D supplementation with physical activity increases fat-free mass and strength, functionality, and quality of life and decreases inflammation in sarcopenic elderly. Am J Clin Nutr. 2016;103(3):830-40.

34. Ling CHY, de Craen AJM, Slagboom PE, Gunn DA, Stokkel MPM, Westendorp RGJ, et al. Accuracy of direct segmental multi-frequency bioimpedance analysis in the assessment of total body and segmental body composition in middle-aged adult population. Clin Nutr Edinb Scotl. 2011; 30(5):610-5.

35. Carvalho VO, Guimarães GV, Carrara D, Bacal F, Bocchi EA. Validation of the Portuguese version of the Minnesota Living with Heart Failure Questionnaire. Arq Bras Cardiol. 2009:93(1):39-44.

36. Schmidt RT, Toews JV. Grip strength as measured by the Jamar dynamometer. Arch Phys Med Rehabil. 1970;51(6):321-7.

37. Spijkerman DC, Snijders CJ, Stijnen T, Lankhorst GJ. Standardization of grip strength measurements. Effects on repeatability and peak force. Scand J Rehabil Med. 1991;23(4):203-6.

38. Bohannon RW. Muscle strength: clinical and prognostic value of hand-grip dynamometry. Curr Opin Clin Nutr Metab Care. 2015;18(5):465-70.

39. Balady GJ, Arena R, Sietsema K, Myers J, Coke L, Fletcher GF, et al. Clinician's guide to cardiopulmonary exercise testing in adults: a scientific statement from the American Heart Association. Circulation. 2010;122(2):191-225.

40. Baumgartner H, Hung J, Bermejo J, Chambers JB, Evangelista A, Griffin BP, et al. Echocardiographic assessment of valve stenosis: EAE/ASE recommendations for clinical practice. Eur J Echocardiogr J Work Group Echocardiogr Eur Soc Cardiol. 2009;10(1):1-25.

41. Lancellotti P, Tribouilloy C, Hagendorff A, Popescu BA, Edvardsen T, Pierard $L A$, et al. Recommendations for the echocardiographic assessment of native valvular regurgitation: an executive summary from the European Association of Cardiovascular Imaging. Eur Heart J Cardiovasc Imaging. 2013;14(7):611-44

42. Cordovil I, Huguenin G, Rosa G, Bello A, Köhler O, de Moraes R, et al. Evaluation of systemic microvascular endothelial function using laser speckle contrast imaging. Microvasc Res. 2012:83(3):376-9. 